\title{
Studies on Parenteral Fluid Therapy in Neurosurgery
}

(First Report)

By

Hideji Senoo

(妹 尾 秀治)

From the Surgical Clinic of Prof. S-T. Katsura, Faculty of Medicine, Tohoku University, Sendai

(Received for publication, April 14, 1959)

Though the recent improvement of operative results have contributed much to the development of various parenteral fluid therapies, the parenteral fluid therapy for brain surgery seems not so satisfactorily advanced, for the researches have been limited to the amount or speed of injection. It is an urgent problem that the parenteral fluid therapy for the patients with high intracranial pressure is sometimes dangerous. Patients without high intracranial pressure, though is not so much exposed to the danger as are the cases with heightened cranial pressure, for example, high intracranial pressures with severe headache, nausea and vomiting may often take fatal consequence by inappropriate application of parenteral fluid therapy, because, it applied to such patients, it may produce more irreversible high intracranial pressure.

It is the purpose of this paper to elucidate the relationship of the various kinds of parenteral fluid and cerebral edema or production of cerebraospinal fluid, experimentally and finally to find an ideal fluid which does not incur hyperintracranial pressure.

In the first step of this investigation, cerebral water contents were measured following cerebral tissue emersion into various kinds of fluid experimentally and then, change of the water contents of the brain was observed following injection of intravenous fluids.

Transposition of the various parenteral fluids into the cerebral tissue or the cerebral fluid was investigated by heavy water as a good tracer of the water injected.

Finally the relationship between intracranial pressure and the various parenteral fluid was studied in this experiments.

A. Change of cerebral water contents due to various kinds of parenteral fluid 


\section{Experimental Methods and Materials}

One hundred and twenty mice weighing about 20 gramms were used and guillotined without anaesthesia.

A section of brain weighing hundred milligramms was taken and put into full moistured chamber and then the section were immersed in various kinds of fluids with serum, for the perid of twenty minutes while preserved in fully saturated oxygen at the temperature of $38^{\circ} \mathrm{C}$. The weight of the brain section was measured before and after the immersion and the increment in weight may be taken to indicate the grade of swelling of the cerebral tissue during the immersion.

The kinds of fluids were as follows : (1) $0.9 \%$ saline (2) $5 \%$ solution of glucose (3) $0.5 \%$ glucose in $0.81 \%$ saline (abv. $0.5 \mathrm{Gl} .0 .81 \mathrm{NaCl}$ ) (4) $2.5 \%$ glucose in $0.45 \%$ saline $(2.5 \mathrm{Gl} .0 .45 \mathrm{NaCl})$ and $(5) 4.5 \%$ glucose in $0.09 \%$ saline (4.5 Gl. $0.09 \mathrm{NaCl})(1)-(5)$ are isotonic solutions.

(6) serum (7) $\mathrm{K}$-solution ( $0.175 \% \mathrm{NaCl}, 0.065 \% \mathrm{KCl}, 7.5 \%$ glucose)

(8) $7.5 \%$ glucose $0.45 \%$ NaCl, (abv. $7.5 \mathrm{Gl} .0 .45 \mathrm{NaCl}$ ).

(9) $9.0 \%$ glucose in 0.18 saline (abv. $9.0 \mathrm{Gl} .0 .18 \mathrm{NaCl}$ ).

(10) $1.0 \%$ glucose $1.62 \%$ saline (abv. $1.0 \mathrm{Gl} .1 .62 \mathrm{NaCl}$ ).

(11) Periston N "Bayer" (7)-(11) are slightly hypertonic. (12) $20 \%$ dextran (13) $20 \%$ glucose (14) $50 \%$ glucose (12)-(14) are hypertonic.

Similar the same experiments were performed mice 48 hours after experimental unilateral frontal lobe puncture.

Using 160 mice, the various solutions were administered intravenously in the dosis of $40 \mathrm{cc} / \mathrm{kg}$ in the rate of $2 \mathrm{cc}$ per minutes.

Sixty minutes after the injection, accurate measurements of one hemisphare each of the brain were performed and then the brain tissue specimens were preserved in thermostatic chamber for the period of fortyeight hours at the temperature of $110^{\circ} \mathrm{C}$.

The difference of brain weight before and after preservation showed the change of the cerebral water content. In addition, mice with injured brain were experimented upon in the same method as in the previous investigation in vitro.

\section{Results}

In vitro: The initial tissue weight increased by $11 \%$ at the highest after immersion in $5 \%$ glucose solution by $6-7 \%$ in $0.9 \%$ saline, $4.5 \mathrm{Gl}$. $0.09 \mathrm{NaCl}, 7.5 \mathrm{Gl} .0 .45 \mathrm{NaCl}$ and $2 \%$ by $2.5 \mathrm{Gl}$. $0.45 \mathrm{NaCl}, \mathrm{K}$-solution, Periston- $\mathrm{N}$, and serum.

Increase by $1 \%$ was found by immersion in $1.0 \mathrm{Gl}$. $1.62 \mathrm{NaCl}$. and $20 \%$ dextran.

Following immersion in $20 \%$ glucose or $50 \%$ glucose solution, the 


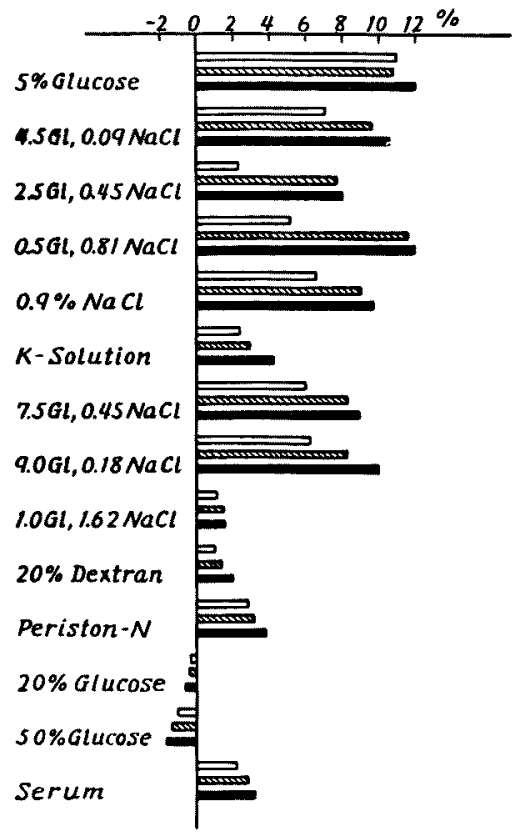

Fig. 1. Swelling of brain tissue in various parenteral fluids. White column : intact mice, shaded column : non-injured side of injured brain mice, black column : injured side of injured brain mice.

cerebral water content was found decreased.

In the case of brain injured mice, the grade of the cerebral swelling was generally higher than that of non-injured mice, and also the brain tissue of the injured side has showed stronger swelling than that of the other side.

Cerebral swelling was observed to the degree of 11 to $12 \%$ of the initial weight in maximum in $5 \%$ Gl. or $0.5 \mathrm{Gl} .0 .81 \mathrm{NaCl}$, and 9 to $10 \%$ by $4.5 \mathrm{Gl} .0 .09 \mathrm{NaCl}, 0.9 \mathrm{NaCl}, 7.5 \mathrm{Gl} .0 .45 \mathrm{NaCl}$ and $9.0 \mathrm{Gl} .0 .18 \mathrm{NaCl}$ solutions.

K-solution, Periston- $\mathrm{N}$ as well as serum caused the cerebral tissue swell by $3 \%$. solution.

Dehydration was observed by use of $20 \%$ glucose or $50 \%$ glucose

In vivo: The mean cerebral water content of the normal mice used as controls was $77.6 \%$. in weight. In the case of injured mice, the cerebral water content was found frankly increased to $78.9 \%$ and $78.3 \%$ of weight in the brain tissue of the injured and the noninjured side, respectively.

The cerebral water content in untreated mice rose to $78.4 \%$ in weight after parenteral fluid therapy with $5 \%$ glucose $4.5 \mathrm{Gl} .0 .09 \mathrm{NaCl}$, and to 


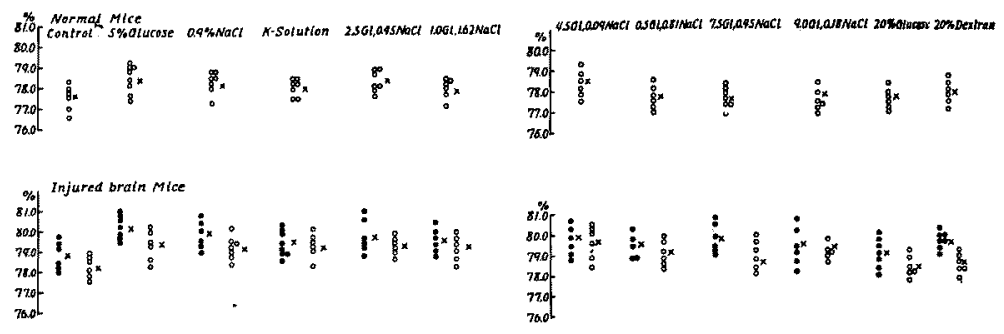

Fig. 2. Change of cerebral water contents giving various parenteral fluids.

In injured brain mice, white circle: non-injured side, black circle: injured side, $x$ : average.

$78.1 \%$ after $0.9 \mathrm{NaCl}$ or $2.5 \mathrm{Gl} .0 .45 \mathrm{NaCl}$.

The change of the cerebral water contents was highest with the above two fluids, followed by $20 \%$ Dextran, K-solution, $0.5 \mathrm{Gl} 0.81 \mathrm{NaCl}$, and $9.0 \mathrm{Gl} .0 .18 \mathrm{NaCl}$ in descending order.

The other kinds of fluids had little influence on the cerebral water content.

The cerebral water content in the injured mice was found more affected in the side injured side than in the intact side.

In the injured side of the brain, the water content increased to the highest value of $80.1 \%$ after $5 \%$ glucose and the increment decreased after 4.5 Gl. $0.09 \mathrm{NaCl}, 0.9 \%$ saline, $7.5 \mathrm{Gl}$. $0.45 \mathrm{NaCl} 2.5$ Gl. $0.45 \mathrm{NaCl}$, $20 \%$ Dextran, 0.5 Gl. 0.81 NaCl, 9.0 Gl. $0.18 \mathrm{NaGl}$, K-solution and 1.0 Gl. $1.62 \mathrm{NaCl}$ in the order named.

After $20 \%$ glucose, scarcely any change occurred in the water content.

In the intact side, the cerebral water content increased most after 4.5 Gl. $0.09 \mathrm{NaCl}$, and less after $5 \%$ glucose, $9.0 \mathrm{Gl}$. $0.18 \mathrm{NaCl}, 0.9 \%$ saline K-solution 2.5 Gl. $0.45 \mathrm{NaCl}, 1.0 \mathrm{Gl}$. $1.62 \mathrm{NaCl}$, and $0.5 \mathrm{Gl} .0 .81$ $\mathrm{NaCl}$ in descending order, $20 \%$ glucose caused little change to the water content of the cerebral tissue.

In the intact half of the brain, 4.5 Gl. $0.09 \mathrm{NaCl}$ had the strongest influence on its water content; the influence decreased in the order of $5 \%$ glucose, 9.0 Gl. $0.18 \mathrm{NaCl}, 0.9 \%$ saline K-solution, 2.5 Gl. $0.45 \mathrm{NaCl}$, 1.0 Gl. $1.62 \mathrm{NaCl}$, and $0.5 \mathrm{Gl} .0 .81 \mathrm{NaCl}, 20 \%$ glucose showed no effect on the water content.

B. Change of water distribution in the cerebral tissue and cerebrospinal fluid by various kinds of fluids therapy

Experimental methods and materials

Using 12 rabbits weighing about $2 \mathrm{~kg}$, each $1 \mathrm{cc}$ per $\mathrm{kg}$ of weight of 
$99.87 \%$ heavy water plus $40 \mathrm{cc}$ per $\mathrm{kg}$ of weight of $5 \%$ glucose were injected intravenously $3 \mathrm{cc}$ per minute and $3 \mathrm{cc}$ of blood from the jugular vein, and $0.8 \mathrm{cc}$ of spinal fluid from the cisterna magna were taken 20 minutes and 60 minutes after the injection.

Immediately after the sampling, the rabbits were guillotined without anaesthesia, and the brain were taken out with meticurous care. Then, the consentration of heavy water in the sample of cerebral tissue, spinal fluid and blood were measured.

- In this experiment, $0.9 \%$ saline, $2.5 \mathrm{Gl}$. $0.45 \mathrm{NaCl}, \mathrm{K}$-solution, and $1.0 \mathrm{Gl}$. 1.62 NaCl, as well as $5 \%$ glucose were applied for investigation. As a control in this study $1 \mathrm{cc}$ per $\mathrm{kg}$ of heavy water was employed.

For measuring the concentration of heavy water, the dropping method ${ }^{11}$ was used, as follows: the sample materials were purified by vacuumdistillation and the distillate was dropped from a specially prepared micropipette into the testing tube containing o-fluolotoluene and the concentration was determined its dropping speed, at $27.3^{\circ} \mathrm{G}$ within the temperature error of $0.001^{\circ} \mathrm{C}$ in a thermostatic chamber. In the measurement, mixture of the cerebral fluid with blood must be avoided.

\section{Results}

In the control experiment, the distribution heavy water blood or cerebrospinal fluid was almost of the same value 20 minutes and 60 minutes after the injection of heavy water, and so the transposition of heavy water seems to stop very soon after the injection.

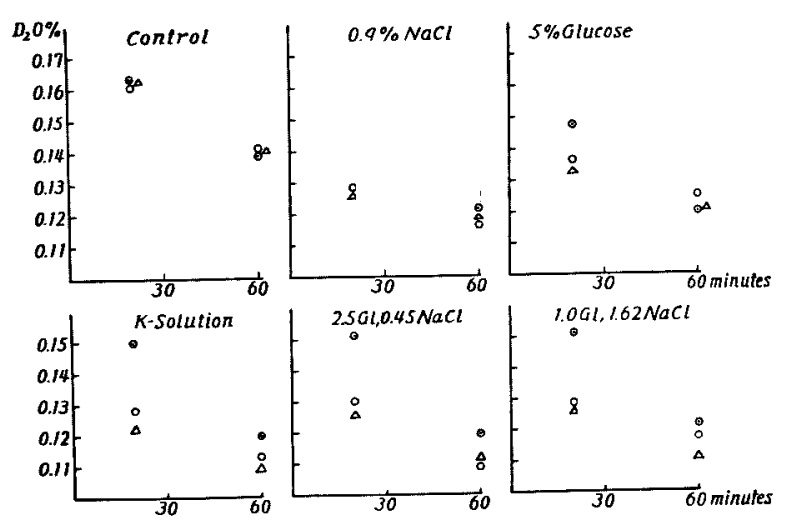

Fig 3. Distribution of $\mathrm{D}_{2} \mathrm{O}$ in cerebral matter and C.S.F. giving various parenteral fluids.

Double circle: $\mathrm{D}_{2} \mathrm{O}$ in blood, circle: $\mathrm{D}_{2} \mathrm{O}$ in C.S.F., triangle: $\mathrm{D}_{2} \mathrm{O}$ in cerebral matter.

Various kinds of parenteral fluid were tested in combination with 
heavy water and the concentration of heavy water in the blood was always almost $0.15 \%, 20$ minutes after the injections started.

The concentration of heavy water in the cerebrospinal fluid was $0.13 \%$ after $5 \%$ glucose and decreased after $2.5 \mathrm{Gl} .0 .45 \mathrm{NaCl}, 1.0 \mathrm{Gl}$. $1.62 \mathrm{NaCl}, 0.9$ saline, in this order.

The lowest value was found after K-solution.

In the cerebral tissues, the change in water distribution showed almost the same tendency as that in the cerebrospinal fluid.

The highest value was found after $5 \%$ glucose, the lowest was after $\mathrm{K}$-solution. The concentration of heavy water in the blood 60 minutes after the injection was about $0.12 \%$ after any kind of fluid.

The concentration of heavy water in cerebrospinal fluid was found the highest after $5 \%$ glucose, followed by $0.9 \%$ saline $1.0 \mathrm{Gl} .1 .62 \mathrm{NaCl}$, $\mathrm{K}$-solution, 2.5 Gl. $0.45 \mathrm{NaCl}$ indescending order.

The concentration of heavy water in the cerebral tissue was the highest after 5\% glucose and decreased after $0.9 \%$ saline, 2.5 Gl. 0.45 $\mathrm{NaCl}, 1.0 \mathrm{Gl}$. 1.62 $\mathrm{NaCl}$ and $\mathrm{K}$-solution in the order-named.

C. Behavior of intracranial pressure after various kinds of parenteral fluid

\section{Experimental method and materials}

Fifteen cats weighing each about $2 \mathrm{~kg}$ were intravenously injected with $40 \mathrm{cc}$ per $\mathrm{kg}$ of weight of $5 \%$ glucose at the rate of $3 \mathrm{cc}$ per $\mathrm{kg}$ per minute and the pressure in cisterna magna was observed for a period of 2 hours. Also experimental studies were performed after causing artificial tumor in their brain by means of injection of Penicillin-ointment into the subdural space 48 hours before the parenteral fluid injection.

\section{Results}

The initial pressure of the cisterna magna of intact cats, was about $50 \mathrm{~mm} \mathrm{H}_{2} \mathrm{O}$. As soon as the parenteral fluid was introduced the pressure increased rapidly and the highest value of $125 \mathrm{~mm} \mathrm{H}_{2} \mathrm{O}$ was found after $5 \%$ glucose. In the order of $0.9 \%$ saline, $2.5 \mathrm{Gl} .0 .45 \mathrm{NaCl}, 1.0 \mathrm{Gl}$. $1.62 \mathrm{NaCl}$ and $\mathrm{K}$-solution, the inerement decreased.

Though the pressure was found to increase after parenteral fluid, the pressure came back to the initial pressure within 10 minutes after the injection started.

Then, the intracranial pressure increased gradually again and reached to the highest point in 40-100 minutes, then decreased gradually to the initial pressure. $96 \mathrm{~mm} \mathrm{H}_{2} \mathrm{O}$ attained after $5 \%$ glucose was the highest level.

In the order of $0.9 \%$ saline, K-solution, $2.5 \mathrm{Gl} .0 .45 \mathrm{NaCl}$ and $1.0 \mathrm{Gl}$. 


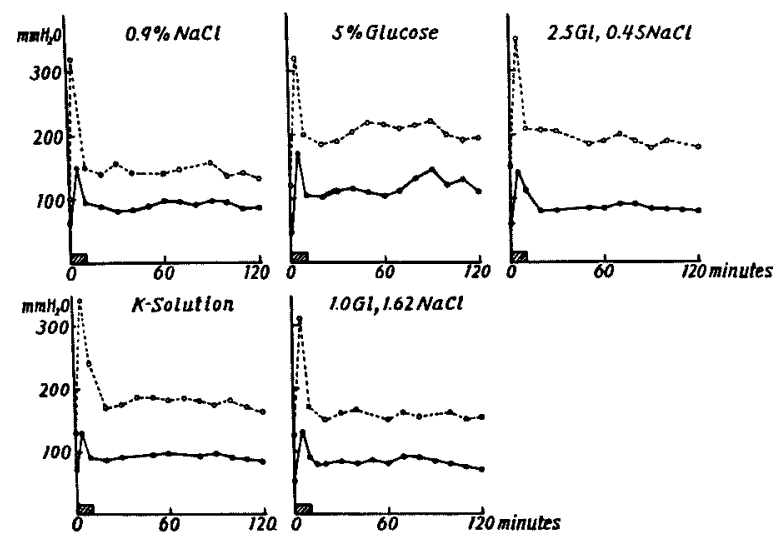

Fib. 4. Change of intracranial pressures giving various parenteral fluids.

Dose- $30 \mathrm{cc}$ per $\mathrm{kg}$, speed $-3 \mathrm{cc}$ per $\mathrm{kg}$ per minute. Dotted line: brain tumor cats, line: intact cats.

$1.62 \mathrm{NaCl}$, the rise of the pressure was smaller.

In the case of cats with artificial brain tumor mentioned above, the initial pressure was about 100 to $150 \mathrm{~mm} \mathrm{H}_{2} \mathrm{O}$, the change of the intracranial pressure was almost the same as that of intact cats, namely, the first increase of intracranial pressure to $200 \mathrm{~mm} \mathrm{H}_{2} \mathrm{O}$ was observed within 10 minutes after the parenteral fluid.

The second increase of intracranial pressure was observed remarkably after $5 \%$ glucose in the value of $100 \mathrm{~mm} \mathrm{H}_{2} \mathrm{O}$.

In the order of $0.9 \%$ saline, K-solution, $2.5 \mathrm{Gl} .0 .45 \mathrm{NaCl}$, and 1.0 GI. $1.62 \mathrm{NaCl}$, the increment of intracranial pressure was decreased.

\section{Discussion and Summary}

In order to find an ideal parenteral fluid which prevents increase of intracranial pressure, namely, causes lesser production of cerebrospinal fluid and prevents cerebral edema, cerebral water contents and the swelling grade of sectioned cerebral tissue after immersion in various kinds of fluids were measured as the first step of this investigation.

In the second step of the investigation, heavy water as a good tracer of water ${ }^{2 / 3) 4}$ was utilized for the study of water distribution in cerebral tissue and cerebrospinal fluid.

The third step of this study was performed in order to elucidate the change of intracranial pressure using the same parenteral fluid.

The swelling grade of sectioned cerebral tissue was found in the lowest degree with $1.0 \mathrm{Gl}$. $1.62 \mathrm{NaCl}$ in the near isotonic solution and in the order of K-solution, $2.5 \mathrm{Gl}$. $0.45 \mathrm{NaCl}, 7.5 \mathrm{Gl} .0 .45 \mathrm{NaCl}, 9.0 \mathrm{Gl}$. 0.18 $\mathrm{NaCl}, 0.9 \%$ saline, $0.5 \mathrm{Gl}, 0.81 \mathrm{NaCl}, 4.5 \mathrm{Gl}, 0.09 \mathrm{NaCl}$, the grade in- 
creased and was the highest with $5 \%$ glucose.

The increase of the cerebral water contents of living animals, was of the lowest value after 1.0 Gl. $1.62 \mathrm{NaCl}$, and in the order of $7.5 \mathrm{Gl}$. $0.45 \mathrm{NaCl}$, K-solution, 0.5 Gl. $0.81 \mathrm{NaCl}, 9.0 \mathrm{Gl}$. $0.18 \mathrm{NaCl}$, and $0.9 \%$ saline, the increment rose higher, to the highest after $5 \%$ glucose. The study of water distribution in the cerebral tissue, and cerebrospinal fluid showed that the transposition of $5 \%$ glucose into cerebrospinal fluid or cerebral tissue was found in the highest grade, and 60 minutes following the start of injection of parenteral fluid was the period of the lowest transposition after K-solution of all the fluids. In the order of $1.0 \mathrm{Gl} .1 .62$ $\mathrm{NaCl}, 2.5 \mathrm{Gl}$. $0.45 \mathrm{NaCl}, 0.9 \%$ saline and $5 \%$ glucose, the transposition into cerebral tissue increased.

The formation of cerebrospinal fluid after parenteral fluid, was the lowest after $2.5 \mathrm{Gl} .0 .45 \mathrm{NaCl}$, and increased in the order of $\mathrm{K}$-solution, 1.0 Gl. $1.62 \mathrm{NaCl}, 0.9 \%$ saline and $5 \%$ glucose.

These experimental results indicated that $\mathrm{K}$-solution caused the lowest shift into the cerebral tissue.

On the intracranial pressure, $1.0 \mathrm{Gl} .1 .62 \mathrm{NaCl}$, caused the minimum increase, and the increment rose in the order of $2.5 \mathrm{Gl} .0 .45 \mathrm{NaCl}, \mathrm{K}$ solution, $0.9 \%$ saline and $5 \%$ glucose. The following conclusion has been obtained that the best parenteral fluid for brain surgery is $1.0 \mathrm{Gl}$. $1.62 \mathrm{NaCl}$, K-solution, followed by $2.5 \mathrm{Gl} .0 .45 \mathrm{NaCl}, 0.9 \%$ saline, and $5 \%$ glucose in the order named.

In the case injured brain, the effects of the various kinds of fluid were just in the same order as above mention, though the troublesome influences $^{5)}$ were found more accentuated than in the case with intact brain.

Because water shift into the cerebrospinal fluid after by $1.0 \mathrm{Gl} .1 .62$ $\mathrm{NaCl}$ solution is higher than after $\mathrm{K}$-solution or $2.5 \mathrm{Gl} .0 .45 \mathrm{NaCl}$, it is advisable to apply intraventricular drainage and as the contents of natrium and chloride in $1.0 \mathrm{Gl} .1 .62 \mathrm{NaCl}$ are twice as much as those in isotonic solution, careful management of serum electrolyte balance is indispensable.

As a matter of fact, serious patients with brain tumor show highly unbalanced electrolyte contents, so $2.5 \mathrm{Gl} .0 .45 \mathrm{NaCl}$ which is prepared as equivalent mixture of $5 \%$ glucose and $0.9 \%$ saline is recommendable, but single administration of $0.9 \%$ saline or $5 \%$ glucose should be avoided.

Why did $5 \%$ glucose show more noxious effect than the other fluids in our study?

Elliot ${ }^{6)}$ stated previously that glucose-shift into cerebral tissue is interfered by electrolytes; on the other hand, the shift goes on until equibalent pressure between the cerebral tissue and blood is attained, when no electrolyte is present.

After administration of $5 \%$ glucose, Fishman") stated that glucose 
TABLE I

Summary of the Experimental Results

Numbers show the order of suitability of the various solutions

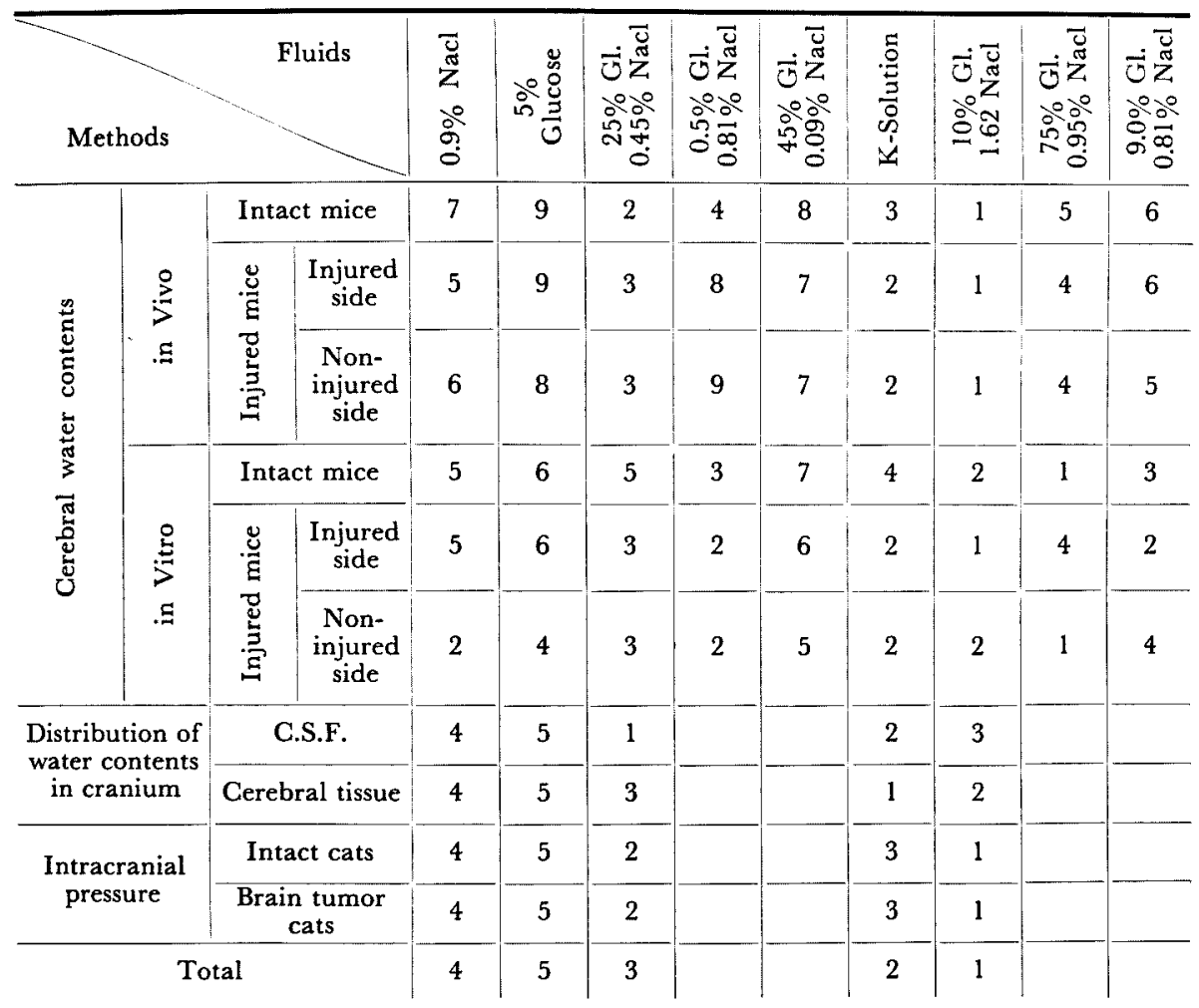

passes gradually through the blood-brain barrier and shifts into the extracellular fluid and then into the intracellular fluid, finally water follows osmotically and at last brain edema develops.

If so, the experimental fact that the increase of intracranial pressure was lower after $0.9 \%$ saline than $5 \%$ glucose becomes difficult to explain.

Fishman and Ide ${ }^{8)}$ answer to this question that water accumulates in the extracellular fluid because the Na-ion are prevented from migrating into the intracellular fluid and does not influence the intracellular fluid, as $\mathbf{5} \%$ glucose solution does.

Therefore, it seems to us that the water distribution of brain after $0.9 \%$ saline showed lower value in comparison with $5 \%$ glucose.

On the other hand, the administration of $2.5 \mathrm{Gl} .0 .45 \mathrm{NaCl}$, showed better results than that of fluids of the above mentioned two groups.

This result may be explained assuming that the glucose-shift can be prevented with elctrolytes and the amount of $\mathrm{Na}$-ions in this solution is 
not so large as in $0.9 \% \mathrm{NaCl}$ and so water accumulates in extracellular fluid in a lower degree.

\section{ConcLusion}

By measuring the grade of swelling of brain tissue immersed in water solutions of various compounds and varying concentrations and then by measuring the cerebral water content after injection of such solutions as parenteral fluids, the solution causing the least change in the volume of the brain tissue and the cerebral water content was determined. Using heavy water which is known as the best tracer of water, the change in the distribution of intracerebral water under the influence of the different parenteral solutions was next followed up. In the last place, the change in the intracranial pressure, that may be taken to represent the summary of all the changes mentioned above, was measured, to determine which of the tested solutions exerts the least effect on the cranial water content and the production of spinal fluid, and causes the least rise of the intracranial pressure. In summary $1.0 \mathrm{Gl} .1 .62 \mathrm{NaCl}$ solution was found to come nearest to the ideal parenteral fluid, followed by $\mathrm{K}$-solution and $2.5 \mathrm{Gl} .0 .45 \mathrm{NaCl}$ solution. The worst and the most to be avoided was single administration of $0.9 \% \mathrm{NaCl}$ or of $5 \%$ glucose.

\section{References}

1) Schloerb, Friis-Hansen, Edelmann, Scheldon, \& Moore, J. Lab. \& Clin. Med., 1951, 37, 653 .

2) Bering, J. Neurosurg., 1952, 9, 275.

3) Bering, ibid., 1954, 11, 234.

4) Edelmann \& Moore, J. Clin. Invest., 1951, 30, 637.

5) Kasai, J.J.S.S. (Jap.), 1956, 57, 467.

6) Elliott, Proc. Soc. Exp. Biol. \& Med., 1946, 63, 234.

7) Fishman, Arch. Neuro. \& Psychiat., 1953, 70, 350.

8) Ide, Okayama I. Z. (Jap.), 1955, 67, 361. 